This is a postprint version of:

Morillo, F. (2016). Public-private interactions reflected through the funding

acknowledgements. Scientometrics, 108(3), 1193-1204.

The final publication is available at Springer via http://dx.doi.org/10.1007/s11192-016-2032-0

\title{
Public-private interactions reflected through the funding acknowledgements
}

\author{
Fernanda Morillo (I)
}

(I) Centre for Human and Social Sciences (CCHS), Spanish National Research Council (CSIC), Albasanz 26-28, 28037 Madrid, Spain.

Corresponding author. E-mail address: fernanda.morillo@cchs.csic.es

\begin{abstract}
Partnership between the public and private sectors has been studied using different methodologies; among them, scientific articles offer an objective way to quantify and assess some of these public-private interactions. The present paper takes advantage of the funding acknowledgements (FA) section included in WoS articles written in English and studies some features of the funded research, such as impact and collaboration. For this purpose, articles with Spain in the address field are selected and retrieved (years 2008-2013), dividing them in two sets: articles with or without FA. Besides, given the large volume of items, the study is focused on groups of articles of each area selected by stratified random sampling. Additionally, those items with a FA section are analysed to identify three types of funding sources: only public, only private, or both sectors. The results show differences between areas in terms of presence of FA and types of funding sectors. On the one hand, in general, articles funded by both the public and private sectors present the best impact, as well as the highest number of authors and organisations. On the other hand, there are important variations in impact and collaboration between areas depending on types of funding sectors. Thus, items funded by both the public and private sectors show the highest significant impact in Clinical Medicine, Life Sciences and Physics, having also greater international collaboration, in most areas, than articles funded only by the public sector. Finally, some limitations of this study are identified and some recommendations for funders and authors are offered.
\end{abstract}


This is a postprint version of:

Morillo, F. (2016). Public-private interactions reflected through the funding

acknowledgements. Scientometrics, 108(3), 1193-1204.

The final publication is available at Springer via http://dx.doi.org/10.1007/s11192-016-2032-0

\section{Keywords}

WoS; Spanish scientific publications; Funding acknowledgements; Funding sectors; Publicprivate interactions; Impact; Collaboration; Statistical Analyses

\section{Introduction}

Several works have stated the importance of collaboration between the public and private sectors to foster knowledge transfer, as it is considered a key to increased innovation and competitiveness. This phenomenon has been studied using different methodologies, such as the analysis of public-private agreements or funding from industry (e.g. Esteve et al. 2012, D'Este et al. 20I3), the evaluation of the products or developments achieved (e.g. Jong and Slavova 2014), or the publication of results from this collaboration in patents or scientific journals (e.g. Breschi and Catalini 2010, Tijssen 2012, Abramo et al. 2009).

Research papers offer an objective way to quantify and assess some of the public-private interactions. In this sense, the attention of most of scientists is focused on co-authorship as an indicator of collaboration, especially when universities publish with firms (e.g. Abramo et al. 2009). However, this analysis can provide only part of the information and it should be completed with other measures to obtain better conclusions about the public-private connections. In this sense, Lundberg et al. (2006), taking into account a particular case, assess the accuracy in identifying university-industry collaborations through co-authorship data complementing it with industrial funding. Indeed, Muscio et al. (2013) observe that government funding complements the private one, fostering collaboration between universities and firms, and stimulating knowledge transfer. In addition, European funding attracts further private sponsorship, since the demanding selection processes guarantee research excellence and most of them promote public-private partnerships, which are more appealing to industry.

The present study takes advantage of the funding acknowledgements (FA) section, included in WoS articles since 2008 (Costas and van Leeuwen 2012). The purpose of the current approach is to complement the information of other methodologies in terms of interactions between the public and private sectors. It will provide interesting data on the features of the research funded only by each sector or by both the public and private sectors, considering 
This is a postprint version of:

Morillo, F. (2016). Public-private interactions reflected through the funding

acknowledgements. Scientometrics, 108(3), 1193-1204.

The final publication is available at Springer via http://dx.doi.org/10.1007/s11192-016-2032-0

aspects such as impact and collaboration. Regarding these characteristics, previous studies pointed out a possible influence of the number of funders on the level of impact (Lewison and Dawson 1998). Nevertheless, other works found evidence of no relation between them, since it could produce just a double-dipping, except in specific circumstances where a positive relation could be detected (Rigby and Julian 2014).

Notwithstanding, the first hypothesis of this work is that, in general, articles funded by both the public and private sectors will provide better results, in terms of impact, than other types of items. In this study, it is expected that these public-private interactions will produce higher impact, because of their interest to different audiences and their possible contribution to knowledge transfer. It is also estimated that those articles will show a greater number of authors and organisations, as well as higher percentages of collaboration. The second hypothesis is that there will be remarkable differences between areas, both with respect to the presence of types of funding sectors and from the viewpoint of impact and collaboration of articles with such funding.

\section{Materials and methodology}

WoS articles with Spain in the address field were selected and retrieved (years 2008-20I3); and only English written papers were considered $(263,100)$, since only those include funding acknowledgements (FA) in these databases. These articles were studied by area and divided in two sets, choosing items with FA $(175,218)$ or without FA $(87,882)$. The areas were made by grouping WoS categories and those firstly analysed were ten: Agriculture, Biology \& Environmental Sciences; Arts \& Humanities; Chemistry; Clinical Medicine; Engineering, Technology; Life Sciences; Mathematics; Multidisciplinary Sciences; Physics; and Social Sciences. However, after learning that, for this period, Thomson-Reuters does not fully collect the FA section of Arts \& Humanities and Social Sciences (except for some selected articles), they were excluded from the sampling study.

For the rest of the work, only eight areas were considered, which included 247,716 articles. Given the large volume of items, stratified random sampling was used to get a total of 7,920 articles from the eight areas. In each area, two samples were selected (with and without FA), obtaining a total of sixteen samples, each with a size of 495 articles. Subsequently, these samples were weighted to give an estimate of the whole population (i.e. the total number of 
This is a postprint version of:

Morillo, F. (2016). Public-private interactions reflected through the funding

acknowledgements. Scientometrics, 108(3), 1193-1204.

The final publication is available at Springer via http://dx.doi.org/10.1007/s11192-016-2032-0

articles, with or without FA, of the corresponding areas), with a margin of error of less than $5 \%$ and a confidence level of $95 \%$. In addition, those articles with a FA section were analysed $(3,960)$ in order to identify their types of funding sectors. In WoS documents, the FA section is divided in fields: Funding Text (which is the exact paragraph that appears in the acknowledgements section of an article), Funding Agency (which includes funding sources that appear in the Funding Text field), and Grant Number. Firstly, the Funding Agency was analysed and, in case of missing information, the Grant Number and Funding Text were also considered. In total, 6,26I unique records were examined (i.e. variants from the Funding Agency and Funding Text). Secondly, all funding sources that appear in these fields (regardless of their country of origin) were classified as belonging to the public or private sectors', thanks to the information provided on web pages. Thirdly, articles with a FA section were grouped according to their corresponding funding sources as only public, only private, or both sectors.

For the three types of funding sectors, some variables were calculated: mean normalised position (NP); proportion of articles in the first quartile (QI); mean number of authors and organisations; and proportion of articles with collaboration (two or more organisations), considering also the proportion of articles with national or international collaboration. The normalised position was calculated by dividing the rank of a journal in a given year and WoS category by the number of journals in this category, subtracting this result from I (Bordons and Barrigón 1992). Finally, some statistical analyses were applied by means of SPSS (IBM Corp. v.23): comparison of column means ( $t$ test) with the Bonferroni correction, pairwise correlations and a Decision Tree (CRT). The Classification and Regression Trees (CRT) are a nonparametric alternative to generalised linear models and can be used as a descriptive and exploratory technique. The procedure uses a binary partitioning algorithm that divides and successively subdivides the population into groups, in order to estimate the values of a dependent variable by identifying several explanatory or predictor variables.

\footnotetext{
' In this paper, the public sector consists of the set of administrations, organisations and firms owned by the government, while the private sector includes organisations with a different ownership (i.e. non-profit institutions, private firms, private universities and private health services). For instance, any national agency was classified as public sector, while any charity was classified as private sector.
} 
This is a postprint version of:

Morillo, F. (2016). Public-private interactions reflected through the funding

acknowledgements. Scientometrics, 108(3), 1193-1204.

The final publication is available at Springer via http://dx.doi.org/10.1007/s11192-016-2032-0

\section{Results}

\section{General data}

WoS articles with Spain in the address field and written in English, in years 2008-2013 $(263,100)$, were collected and divided in two sets: items with $(67 \%)$ or without FA $(33 \%)$. As it can be seen in Figure I, there were remarkable differences among areas with regard to funding recognition. Considering that, in the analysed period, WoS does not fully include FA for Arts \& Humanities and Social Sciences, these areas had a very low representation. While in Arts \& Humanities, less than $16 \%$ of the articles mentioned funding sources and, in Social Sciences, less than $26 \%$, in Multidisciplinary Sciences, nearly $85 \%$ of the articles had FA. In fact, apart from the first two areas, only Clinical Medicine presented percentages of articles with FA under the average.

Figure I. Percentages of articles with or without funding acknowledgements (FA) by area (all articles, WoS 2008-2013)
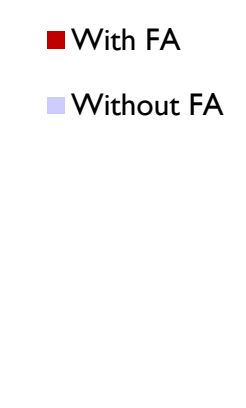

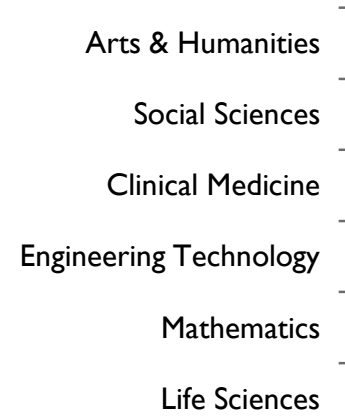

Agriculture, Biology \& Environmental Sciences

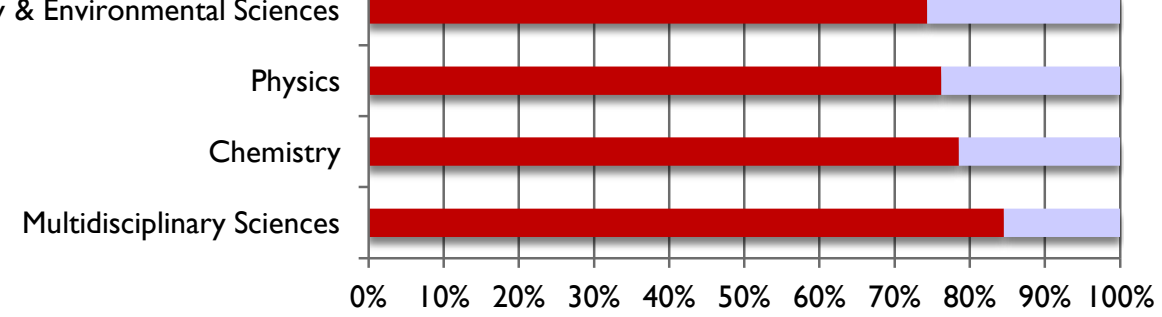

\section{Sampling study}

Having confirmed the underrepresentation of Arts \& Humanities and Social Sciences, these areas were excluded from the rest of the study. Groups of articles of each area, with or without FA, were selected by stratified random sampling (with the remaining eight areas) and 
This is a postprint version of:

Morillo, F. (2016). Public-private interactions reflected through the funding

acknowledgements. Scientometrics, 108(3), 1193-1204.

The final publication is available at Springer via http://dx.doi.org/10.1007/s11192-016-2032-0

were weighted to give an estimate of the whole population. Additionally, those items with a FA section were analysed and classified in three types of funding sources: only public, only private, or both sectors. Overall, $79 \%$ of the articles were funded only by the public sector, $18 \%$ had public and private funding, and $3 \%$ were funded only by the private sector. There were notable variations among areas, as observed in Figure 2. On the one hand, Mathematics presented the highest percentage of articles funded only by the public sector (almost 93\%). On the other hand, Multidisciplinary Sciences showed the highest percentage of articles funded by both the public and private sectors (33\%), followed by Life Sciences and Clinical Medicine (both with $28 \%$ ). Finally, the greatest percentage of only private funding could be found in articles published in the Clinical Medicine area (17\%).

Figure 2. Percentages of articles by funding sector and area (weighted samples with FA, WoS 2008-20|3)

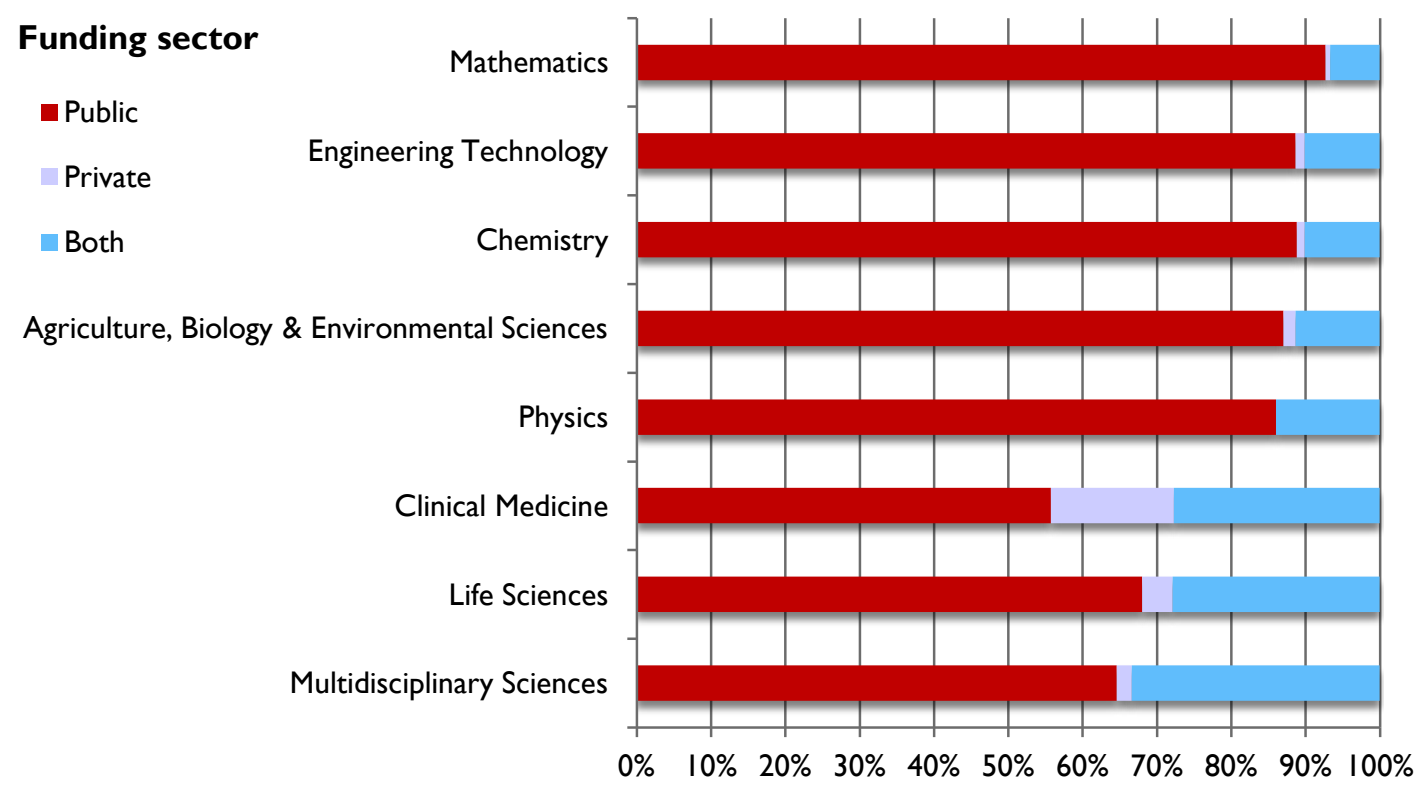

In general, with regard to impact and collaboration, significant differences between types of funding sectors were found, as reflected in Table I. Thus, means in the same row are compared using a $t$ test and those that do not share subscripts differ at $p<.05$. For example, 48.33 (with the subscript letter $b$ ) is the mean value of authors for the articles funded by both the public and private sectors. This value is significantly different from the one of articles funded only by the private sector ( 8.87 , with the subscript letter $a$ ) and from the one of articles funded only by the public sector (6.70, with the subscript letter $a$ ). In general, articles funded by both the public and private sectors obtained the greatest values for almost 
This is a postprint version of:

Morillo, F. (2016). Public-private interactions reflected through the funding

acknowledgements. Scientometrics, 108(3), 1193-1204.

The final publication is available at Springer via http://dx.doi.org/10.1007/s11192-016-2032-0

all the analysed variables (NP, QI, mean number of authors and organisations, and proportion of articles with national collaboration). In addition, concerning values of total and international collaboration, they were significantly higher than those funded only by the public sector. Besides, considering that there was a high mean number of authors in articles funded by both the public and private sectors, it was reasonable to assume that there would be some association with NP. To check this, pairwise correlations between NP and number of authors were performed for the whole set and for each type of funding sector. The results revealed little or no relationship between the two variables $(p>.05)$, supporting the fact that items funded by both the public and private sectors obtained generally the highest values in NP, regardless of the number of authors.

Table I. Mean values of impact and collaboration by funding sector (weighted samples with FA, WoS 2008-2013)

\begin{tabular}{|lrrr|}
\multicolumn{4}{c}{ Funding sector } \\
\hline NP & Public & Private & \multicolumn{1}{c|}{ Both } \\
\hline QI & $.75_{\mathrm{a}}$ & $.7 \mathrm{I}_{\mathrm{b}}$ & $.80_{\mathrm{c}}$ \\
\hline Auth & $.64 \mathrm{a}$ & $.54 \mathrm{~b}$ & $.75_{\mathrm{c}}$ \\
\hline Org & $6.70_{\mathrm{a}}$ & $8.87_{\mathrm{a}}$ & $48.33_{\mathrm{b}}$ \\
\hline Coll & $3.15_{\mathrm{a}}$ & $6.98_{\mathrm{b}}$ & $9.18_{\mathrm{c}}$ \\
\hline Coll_Nat & $.78_{\mathrm{a}}$ & $.92_{\mathrm{b}}$ & $.89_{\mathrm{b}}$ \\
\hline Coll_Int & $.48_{\mathrm{a}}$ & $.42_{\mathrm{a}}$ & $.53_{\mathrm{b}}$ \\
\hline
\end{tabular}

Note: Means in the same row that do not share subscripts differ at $\mathrm{p}<.05$.

NP: mean normalised position. QI: proportion of articles in the first quartile. Auth: mean number of authors. Org: mean number of organisations. Coll: proportion of articles with collaboration. Coll_Nat: proportion of articles with national collaboration. Coll_Int: proportion of articles with international collaboration.

In order to analyse research performance as measured by the value of NP, a Decision Tree (CRT) was created with all samples, with or without FA (Figure 3 ). This CRT was generated to explore which input variables have an effect on NP (dependent variable), considering, for the categorical response variables, funding acknowledgements (FA), funding sector and international collaboration (explanatory variables). The FA variable was separated in a split at the root node, indicating that the value of NP was significantly higher $(P<.05)$ for articles with funding acknowledgements $(0.76 \mathrm{I})$, as compared to those without funding acknowledgments (0.660). In addition, a significant increase of NP $(p<.05)$ could be found in those publications with funding from both the public and private sectors $(0.810)$ and, even more, with international collaboration $(0.837)$. These results imply that values of the 
This is a postprint version of:

Morillo, F. (2016). Public-private interactions reflected through the funding acknowledgements. Scientometrics, 108(3), 1193-1204.

The final publication is available at Springer via http://dx.doi.org/10.1007/s11192-016-2032-0

dependent variable (NP) can be predicted in a new dataset based on the values of the explanatory variables, with a risk estimate of 0.054 .

Figure 3. Decision Tree (CRT) of normalised position by funding acknowledgements, funding sector and international collaboration (unweighted samples, WoS 2008-20 I3)

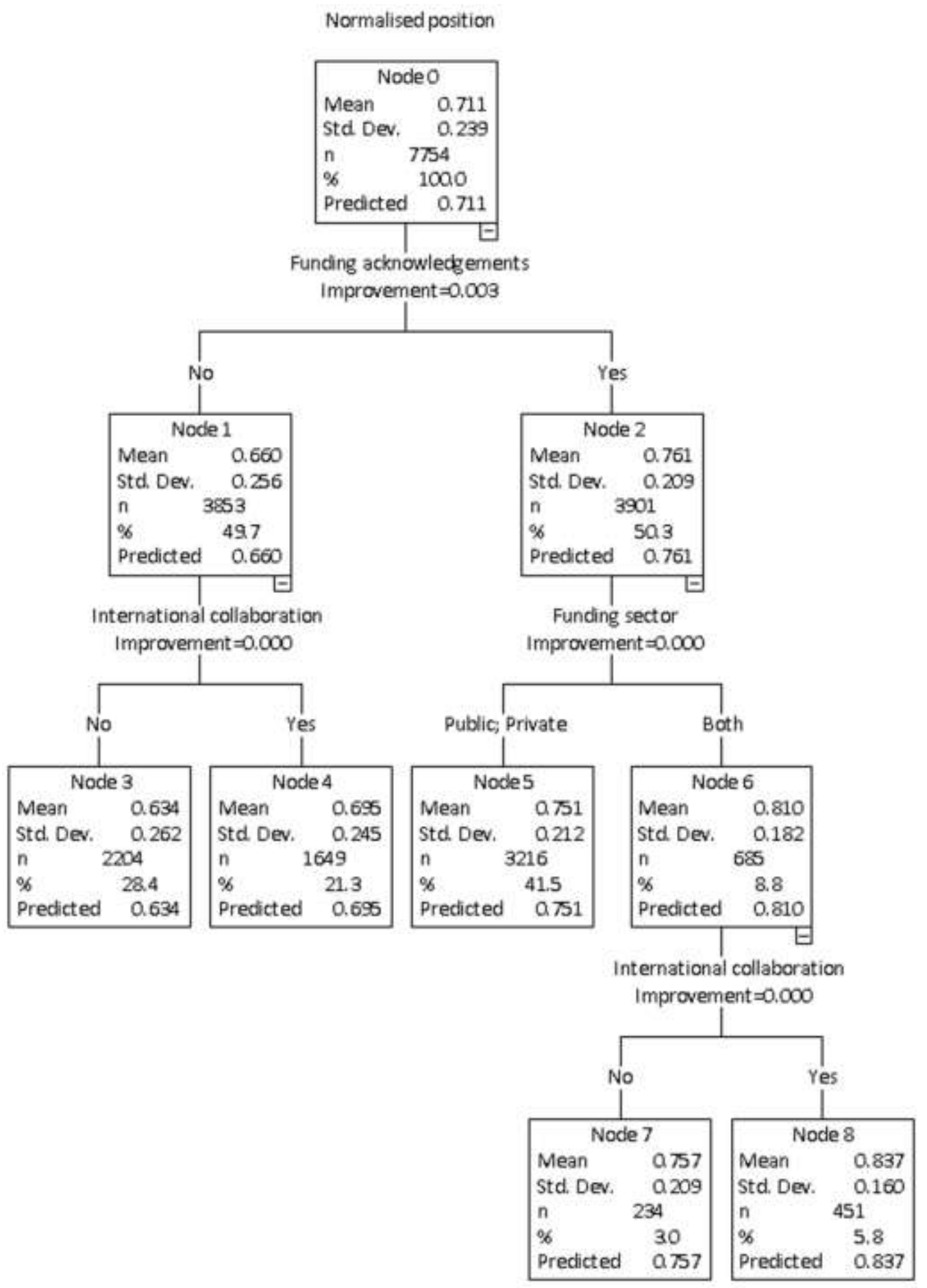


This is a postprint version of:

Morillo, F. (2016). Public-private interactions reflected through the funding

acknowledgements. Scientometrics, 108(3), 1193-1204.

The final publication is available at Springer via http://dx.doi.org/10.1007/s11192-016-2032-0

Finally, variations between areas were found in impact and collaboration by type of funding sector (Table 2). For instance, in Chemistry, Mathematics, and Multidisciplinary Sciences, significant differences between funding sectors were found only in one or two variables. In the case of Chemistry, there was a significant smaller impact for articles funded only by the private sector than for the rest (both for NP and for QI), despite the similarity of other characteristics. In Mathematics, the only disparities were seen in international collaboration, where articles with only public funding had lower values than those funded by both the public and private sectors, with no significant difference with articles funded only by the private sector. In Multidisciplinary Sciences, disparities appeared between articles with only public funding and those funded by both the public and private sectors in NP and in international collaboration (reflecting lower values), again with no difference with articles funded only by the private sector. Notwithstanding, for the rest of the areas, significant differences between at least two funding sectors were found in most variables. In Clinical Medicine, articles funded by both the public and private sectors had significant higher values for NP than the rest, as in Life Sciences and Physics, which also showed greater values for QI. In addition, the last one had distinctly different results in its only two types of funding sectors, being the articles funded by both the public and private sectors the ones with the highest values.

Table 2. Mean values of impact and collaboration by funding sector and area (weighted samples with FA, WoS 2008-20I3)

\begin{tabular}{|c|c|c|c|c|}
\hline \multirow{2}{*}{ Areas } & & \multicolumn{3}{|c|}{ Funding sector } \\
\hline & & Public & Private & Both \\
\hline \multirow{7}{*}{$\begin{array}{l}\text { Agriculture, Biology \& } \\
\text { Environmental Sciences }\end{array}$} & NP & $.75 \mathrm{a}$ & $.59 b$ & $.74 a$ \\
\hline & QI & $.63 a$ & $.25 b$ & $.64_{a}$ \\
\hline & Auth & $5.00_{a}$ & $5.00_{\mathrm{a}, \mathrm{b}}$ & $5.80_{b}$ \\
\hline & Org & $2.69 a$ & $2.38_{a, b}$ & $3.36 \mathrm{~b}$ \\
\hline & Coll & $.75 \mathrm{a}$ & $1.00_{b}$ & $.84_{a, b}$ \\
\hline & Coll_Nat & $.46 a$ & $.12 \mathrm{~b}$ & $.43 a$ \\
\hline & Coll_Int & $.43 a$ & $1.00_{b}$ & $.57_{c}$ \\
\hline \multirow{7}{*}{ Chemistry } & NP & $.80_{a}$ & $.60_{b}$ & $.79_{a}$ \\
\hline & QI & $.72 \mathrm{a}$ & $.20_{b}$ & $.64 a$ \\
\hline & Auth & $5.22_{a}$ & $5.00_{a}$ & $5.42_{a}$ \\
\hline & Org & $2.54 a$ & $2.60_{a}$ & $2.34 a$ \\
\hline & Coll & $.74 a$ & $.60 \mathrm{a}$ & $.66 a$ \\
\hline & Coll_Nat & $.44 a$ & $.40_{a}$ & $.32 \mathrm{a}$ \\
\hline & Coll_Int & $.44_{a}$ & $.40_{a}$ & $.40_{a}$ \\
\hline
\end{tabular}


This is a postprint version of:

Morillo, F. (2016). Public-private interactions reflected through the funding acknowledgements. Scientometrics, 108(3), 1193-1204.

The final publication is available at Springer via http://dx.doi.org/10.1007/s11192-016-2032-0

\begin{tabular}{|c|c|c|c|c|}
\hline \multirow{2}{*}{ Areas } & & \multicolumn{3}{|c|}{ Funding sector } \\
\hline & & Public & Private & Both \\
\hline \multirow{7}{*}{ Clinical Medicine } & NP & $.74 a$ & $.76 a$ & $.8 \mathrm{I}_{\mathrm{b}}$ \\
\hline & QI & $.57 \mathrm{a}$ & $.65_{a, b}$ & $.77_{b}$ \\
\hline & Auth & $7.72 \mathrm{a}$ & $10.32 b$ & $12.16 \mathrm{~b}$ \\
\hline & Org & $4.63 a$ & $8.43 b$ & $7.94 b$ \\
\hline & Coll & $.86 a$ & $.95 \mathrm{~b}$ & $.96 \mathrm{~b}$ \\
\hline & Coll_Nat & $.68 \mathrm{a}$ & $.40_{b}$ & $.62 \mathrm{a}$ \\
\hline & Coll_Int & $.45_{a}$ & $.73 b$ & $.64 b$ \\
\hline \multirow{7}{*}{ Engineering, Technology } & NP & $.75 a$ & $.73 a$ & $.79_{a}$ \\
\hline & QI & $.65 \mathrm{a}$ & $.50 \mathrm{a}$ & $.73 a$ \\
\hline & Auth & $4.84 a$ & $5.00_{a, b}$ & $13.32 \mathrm{~b}$ \\
\hline & Org & $2.45_{a}$ & $2.17_{\mathrm{a}, \mathrm{b}}$ & $3.92_{b}$ \\
\hline & Coll & $.70 \mathrm{a}$ & $.67_{a, b}$ & $.84 b$ \\
\hline & Coll_Nat & $.44 a$ & $.33 \mathrm{a}$ & $.52 \mathrm{a}$ \\
\hline & Coll_Int & $.38 \mathrm{a}$ & $.50_{\mathrm{a}, \mathrm{b}}$ & $.60_{b}$ \\
\hline \multirow{7}{*}{ Life Sciences } & NP & $.7 \mathrm{I}_{\mathrm{a}}$ & $.63 b$ & $.79 c$ \\
\hline & QI & $.56 \mathrm{a}$ & $.40_{a}$ & $.76 b$ \\
\hline & Auth & $6.10_{a}$ & $8.40_{b}$ & $8.07 b$ \\
\hline & Org & $3.03 a$ & $7.20_{b}$ & $4.53 c$ \\
\hline & Coll & $.80_{a}$ & $.95 b$ & $.9 \mathrm{I}_{\mathrm{b}}$ \\
\hline & Coll_Nat & $.55 \mathrm{a}$ & $.60 \mathrm{a}$ & $.52 \mathrm{a}$ \\
\hline & Coll_Int & $.40_{a}$ & $.50_{a, b}$ & $.6 \mathrm{I}_{\mathrm{b}}$ \\
\hline \multirow{7}{*}{ Mathematics } & NP & $.69 a$ & $.54 a$ & $.65 a$ \\
\hline & QI & $.53 a$ & $.33 a$ & $.48 a$ \\
\hline & Auth & $2.77_{a}$ & $2.33_{a}$ & $2.94 a$ \\
\hline & Org & $2.2 \mathrm{a}_{\mathrm{a}}$ & $1.67 \mathrm{a}$ & $2.73_{a}$ \\
\hline & Coll & $.73 a$ & $.67 \mathrm{a}$ & $.88_{a}$ \\
\hline & Coll_Nat & $.36 \mathrm{a}$ & $.33 \mathrm{a}$ & $.33 a$ \\
\hline & Coll_Int & $.47 \mathrm{a}$ & $.33_{a, b}$ & $.76 b$ \\
\hline \multirow{7}{*}{ Multidisciplinary Sciences } & NP & $.8 \mathrm{I}_{\mathrm{a}}$ & $.80_{a, b}$ & $.89 b$ \\
\hline & QI & $.86 a$ & $.90 \mathrm{a}$ & $.98 \mathrm{a}$ \\
\hline & Auth & $7.3 \mathrm{I}_{\mathrm{a}}$ & $8.60_{a}$ & $19.03 \mathrm{a}$ \\
\hline & Org & $4.58 \mathrm{a}$ & $6.10_{a}$ & $8.83_{a}$ \\
\hline & Coll & $.85 a$ & $.90 \mathrm{a}$ & $.98 \mathrm{a}$ \\
\hline & Coll_Nat & $.56 \mathrm{a}$ & $.50 \mathrm{a}$ & $.67 a$ \\
\hline & Coll_Int & $.53 \mathrm{a}$ & $.50_{\mathrm{a}, \mathrm{b}}$ & $.75 b$ \\
\hline
\end{tabular}


This is a postprint version of:

Morillo, F. (2016). Public-private interactions reflected through the funding

acknowledgements. Scientometrics, 108(3), 1193-1204.

The final publication is available at Springer via http://dx.doi.org/10.1007/s11192-016-2032-0

\begin{tabular}{|c|c|c|c|c|}
\hline \multirow{2}{*}{\multicolumn{2}{|c|}{ Areas }} & \multicolumn{3}{|c|}{ Funding sector } \\
\hline & & Public & Private & Both \\
\hline \multirow{7}{*}{ Physics } & NP & $.77_{\mathrm{a}}$ & .1 & $.8 \mathrm{I}_{\mathrm{b}}$ \\
\hline & QI & $.67 \mathrm{a}$ & .1 & $.80_{b}$ \\
\hline & Auth & $13.03 \mathrm{a}$ &. & $292.12 \mathrm{~b}$ \\
\hline & Org & $4.49 \mathrm{a}$ & .1 & $34.99 b$ \\
\hline & Coll & $.86_{a}$ & .1 & $.93_{b}$ \\
\hline & Coll_Nat & $.48 \mathrm{a}$ & .1 & $.58 \mathrm{~b}$ \\
\hline & Coll_Int & $.66 \mathrm{a}$ & .1 & $.84 b$ \\
\hline
\end{tabular}

Note: Means in the same row that do not share subscripts differ at $\mathrm{p}<.05$.

NP: mean normalised position. QI: proportion of articles in the first quartile. Auth: mean number of authors. Org: mean number of organisations. Coll: proportion of articles with collaboration. Coll_Nat: proportion of articles with national collaboration. Coll_Int: proportion of articles with international collaboration.

\section{Discussion and conclusions}

This study provides an overview of the characteristics of articles with Spain in the address field, with or without FA. On the one hand, variations between areas in terms of presence of FA were detected, as previously pointed by Díaz-Faes and Bordons (2014). Nevertheless, percentages of articles with FA differed from those found in that work, although, the distribution was almost the same, except for Multidisciplinary Sciences that ranked first, when considering the wider period analysed in this paper. On the other hand, results showed that the public sector was the main funder, although with different proportions by area. Thus, Clinical Medicine had the lowest proportion of articles with only public funding (56\%), while Mathematics had the largest percentage (93\%). Concerning the proportion of articles funded by both the public and private sectors, Multidisciplinary Sciences was the area with the highest percentage, followed by Life Sciences and Clinical Medicine.

Overall, the research funded by both the public and private sectors had the best impact (i.e. higher values of NP and QI), as expected in the first hypothesis. In addition, it had the highest number of authors and organisations, and the greatest proportion of national collaboration. Besides, it was observed that there was little or no relationship between NP and mean number of authors, concluding that, in general, articles funded by both the public and private sectors obtained the highest values in NP, regardless of the number of authors. Furthermore, when analysing what explanatory variables had an effect on the impact, it was observed that NP values were higher for articles with FA, funded by both the public and 
This is a postprint version of:

Morillo, F. (2016). Public-private interactions reflected through the funding

acknowledgements. Scientometrics, 108(3), 1193-1204.

The final publication is available at Springer via http://dx.doi.org/10.1007/s11192-016-2032-0

private sectors, and with international collaboration. Similarly, Rigby and Julian (2014) stated that when funding comes from a diversity of sources, due to the nature and extent of the research under consideration, there might be some incremental effect in the citation count. For their part, Wang and Shapira (20II) stated that stronger competitiveness to access funds is linked with high research impact, something that it is reasonably to find when presenting proposals to different funders.

With respect to the second hypothesis, there were notable variations between areas, in impact and collaboration, according to their types of funding sectors. On the one hand, Engineering, Technology and Mathematics revealed no significant differences in NP between funding sectors. However, Agriculture, Biology \& Environmental Sciences and Chemistry showed higher NP for articles funded by both the public and private sectors than for those funded only by the private sector, and, in Multidisciplinary Sciences, than for those funded only by the public sector. With regard to Clinical Medicine, Life Sciences, and Physics, these areas presented the highest NP for articles funded by both the public and private sectors. Besides, Physics had the greatest values in all the analysed variables for this type of funding sector. On the other hand, Chemistry revealed no significant differences in any of the collaboration variables between funding sectors, while, for five other areas (Clinical Medicine, Engineering, Technology, Life Sciences, Mathematics and Multidisciplinary Sciences), articles funded by both the public and private sectors showed higher international collaboration than those funded only by the public sector.

Although not the object of this study, it is important to consider the type of private sponsors that fund research. Even without an accurate identification of funders, the most common private organisations mentioned in FA were the non-profit organisations (NPO), in around half of the articles, followed by firms (in around one third of the publications). In addition, in articles funded only by private organisations, firms had the largest presence in FA (in around half of publications). In fact, in their article, Lundberg et al. (2006) observed that one-third of the firms that provided funding did not publish with university; therefore, it is relevant to analyse their other types of interactions that occur beyond co-authorship. In addition, it is also important to analyse the presence of NPO, since they have greater flexibility to fund new ideas or unconventional methodologies (Sommer 2005) and may even offer connections with the public sector. Indeed, previous studies (Morillo and Efrain-Garcia 2015) showed how Technology Centres, a type of NPO, acted as links between public 
This is a postprint version of:

Morillo, F. (2016). Public-private interactions reflected through the funding

acknowledgements. Scientometrics, 108(3), 1193-1204.

The final publication is available at Springer via http://dx.doi.org/10.1007/s11192-016-2032-0

institutions and firms, providing access to research, technology and development and fostering firms' innovation and competitiveness.

\section{Limitations and recommendations}

Firstly, it should be noted that some of the articles funded by both the public and private sectors are the result of contracts or agreements made between the public and private entities to solve a particular problem. However, other items offer other kind of interactions that may not reflect a true research transfer, being difficult to determine when this happens. In addition, as pointed by Wang and Shapira (20I I), not all the funding results are published, since some outcomes are concealed or revealed only through patents or other technological developments. Another limitation is that, in WoS, funders are obtained from the acknowledgments section of articles, which sometimes includes institutions mentioned in the statements of conflicts of interest that can be wrongly considered as funding sources (Lewison and Sullivan 20I5).

Secondly, the nationality of funding sources was not examined in this document, given the wide variety of the analysed funders and considering that WoS fields do not always include information about the country. However, it is supposed that articles funded by both the public and private sectors may include international sponsorship, which has an influence on the performance of this type of funding sector. For this reason, some suggestions can be drawn:

- For funders, it would be appropriate to develop policies about how to be mentioned, including the country or region, especially in the case of firms. Some efforts have been made in this sense by well-recognised funding schemes (e.g. European Union).

- For authors, following certain standards would result in a better assessment of their research. In particular, mentioning the number of project (or its title), without specifying the agency and country/region that has granted it, hampers the identification of the corresponding results.

Finally, this work has not taken into account the number of funders of each article, so it is not possible to estimate the influence of this number on the results. In any case, it is understood that items funded from both the public and private sectors contain at least two funders, while those articles funded only by the public or private sector can contain just one 
This is a postprint version of:

Morillo, F. (2016). Public-private interactions reflected through the funding

acknowledgements. Scientometrics, 108(3), 1193-1204.

The final publication is available at Springer via http://dx.doi.org/10.1007/s11192-016-2032-0

funder. Besides, other important elements to consider, not shown in the FA and that can influence the research results, are the amounts received through funding. In fact, Sandström (2008) found a significant association between two input variables (number of grants and money received) and the number of publications and citations. Subsequent studies will benefit from the inclusion of new data (number and nationality of funders, and amount of funding) in order to assess their influence on research results.

\section{Acknowledgements}

This work is supported by the Spanish Ministry of Science and Innovation (Grant CSO20 II-25I02) and the Spanish Ministry of Economy and Competitiveness (Grant CSO2014-57826-P). Valuable assistance and/or comments are also greatly acknowledged from the Statistical Analysis Unit (CCHS), and from María Bordons, Javier Aparicio, Borja González-Albo and two anonymous reviewers.

\section{References}

Abramo, G.; D'Angelo C.A.; DiCosta, F. \& Solazzi, M. (2009) University-industry collaboration in Italy: A bibliometric examination. Technovation, 29(6-7), 498-507. doi:10.1016/j.technovation.2008.11.003

Bordons, M., \& Barrigón, S. (1992). Bibliometric analysis of publications of Spanish pharmacologists in the SCI (1984-89). Part II: Contribution to subfields other than "pharmacology \& pharmacy"(ISI). Scientometrics, 25(3), 425-446. doi:10.1007/BF02016930

Breschi, S. \& Catalini, C. (20I0). Tracing the links between science and technology: An exploratory analysis of scientists' and inventors' networks. Research Policy, 39(I), 14-26.

doi:10.1016/j.respol.2009.11.004

Costas, R., \& van Leeuwen, T. N. (20I2). Approaching the "reward triangle": General analysis of the presence of funding acknowledgments and "peer interactive communication" in scientific publications. Journal of the American Society for Information Science and Technology, 63(8), I647-I66I. doi:10.1002/asi.22692

D'Este, P.; Tang, P.; Mahdi, S.; Neely, A. \& Sánchez-Barrioluengo, M. (20I3). The pursuit of academic excellence and business engagement: is it irreconcilable? Scientometrics, 95(2), 48I-502.

doi: |0.1007/s | | |92-0|3-0955-2 
This is a postprint version of:

Morillo, F. (2016). Public-private interactions reflected through the funding

acknowledgements. Scientometrics, 108(3), 1193-1204.

The final publication is available at Springer via http://dx.doi.org/10.1007/s11192-016-2032-0

Díaz-Faes, A.A., \& Bordons, M. (2014). Acknowledgements in scientific publications: presence in Spanish science and text patterns across disciplines. Journal of the Association for Information Science and Technology, 65(9), 1834-1849. doi:10.1002/asi.2308I

Esteve, M.; Ysa, T. \& Longoa, F. (2012). The Creation of Innovation Through Public-private Collaboration. Revista Española de Cardiología, 65(9), 835-842. doi:I0.1016/j.rec.2012.04.006

Jong, S., \& Slavova, K. (2014). When publications lead to products: The open science conundrum in new product development. Research Policy, 43(4), 645-654. doi: 10.1016/j.respol.2013.12.009

Lewison, G., \& Dawson, G. (1998). The effect of funding on the outputs of biomedical research. Scientometrics, 4I(I-2), 17-27. doi:I0.1007/BF02457963

Lewison, G., \& Sullivan, R. (2015). Conflicts of interest statements on biomedical papers. Scientometrics, I02(3), 215I-2159. doi: |0.1007/s | | |92-0|4-|507-0

Lundberg, J.; Tomson, G.; Lundkvist, I.; Skår, J.; Brommels, M. (2006). Collaboration uncovered: Exploring the adequacy of measuring university-industry collaboration through co-authorship and funding. Scientometrics, 69(3), 575-89. doi:10.1007/s | | |92-006-0170-5

Morillo, F. \& Efrain-Garcia, P. (2015). A bibliometric analysis of Technology Centres. Scientometrics, 104(3), 685-7|3. doi:|0.1007/s | || 92-0|5-163|-5

Muscio, A., Quaglione, D., \& Vallanti, G. (20/3). Does government funding complement or substitute private research funding to universities?. Research Policy, 42(I), 63-75.

doi:10.1016/j.respol.2012.04.010

Rigby, J., \& Julian, K. (20I4). On the horns of a dilemma: does more funding for research lead to more research or a waste of resources that calls for optimization of researcher portfolios? An analysis using funding acknowledgement data. Scientometrics, I0I(2), 1067-1075.

doi:|0.|007/s | || 92-0|4-|259-x

Sandström, U. (2008). Research quality and diversity of funding: A model for relating research money to output of research. Scientometrics, 79(2), 341-349. doi:I0.1007/s I | |92-009-0422-2

Sommer, S. (2005). Bibliometric analysis and private research funding. Scientometrics, 62(I), 165-I7I. doi: |0.1007/s | | | 92-005-00| I-y

Tijssen, R. J. (20I2). Co-authored research publications and strategic analysis of public-private collaboration. Research evaluation, 21 (3), 204-215. doi:I0.1093/reseval/rvs0 I3

Wang, J., \& Shapira, P. (20II). Funding acknowledgement analysis: an enhanced tool to investigate research sponsorship impacts: the case of nanotechnology. Scientometrics, 87(3), 563-586.

doi: |0.1007/s | || $92-0||-0362-5$ 